\title{
The Perfect Strategy of the Leader's Character of College Education Teams
}

\author{
Weijiao Ye \\ School of Anxi College of Tea Science \\ Fujian Agriculture and Forestry University \\ Quanzhou, China.
}

\author{
Ziqiang Li \\ School of Anxi College of Tea Science \\ Fujian Agriculture and Forestry University \\ Quanzhou, China.
}

\author{
Jiangfan Yang \\ School of Economics \\ Fujian Agriculture and Forestry University \\ Fuzhou, China.
}

\begin{abstract}
In order to improve the leadership of the leaders of college education teams, promote cooperation between the members of the education team, and enhance the team's comprehensive strength and cohesion, this paper, based on the classification of personality in psychology and the relevant theories of leaders, explores the perfection of the leadership character of college education team by analyzing the relationship between the leadership character of college education team and team building. Finally, the perfection strategy of the leader's character is concluded, which indicates the leader himself should keep a low profile, face the weakness of the character, maintain an open mind, change the personality weakness, and put forward the characteristics of the university education leader from the perspectives of professionalism, system and subject.
\end{abstract}

Keywords-college education team leader; Team building; character; Perfect policy

\section{INTRODUCTION}

As the leader of the team organization and the core member of the team organization, the leaders of the university education team play an important role in the overall development of the team, project task assignment, information dissemination operation, and incentives for members' rewards and punishments. Their own personality differences often affect their project decisions, which in turn lead to different development directions of the team organization [1]. Personality reflects the social attributes of personality, and the core of personality differences between individuals is the difference in personality. The study found that the personality differences of college education team leaders have a completely different influence on their leadership effects [2]. Therefore, more and more scholars in the academic world regard the leadership character of college education team as an extremely important consideration for organizational development. However, most of the mainstream researches mainly focus on the relationship between the leadership characteristics of college education team and team performance, the cultural atmosphere of colleges and universities, and the enthusiasm of team members. The leaders of college education teams are not enough to understand and improve their

Fujian “2011 Collaborative Innovation Center” China Oolong Tea Industry Collaborative Innovation Center Special personality. Therefore, this paper attempts to explore the perfection of college education team leaders' self-characteristics by analyzing the relationship between college education team leaders' personality and team-building and provides reference and enlightenment for current university education team leaders to overcome and improve their own personality weaknesses.

\section{PERSONALITY CHARACTERISTICS AND TEAM BUILDING OF UNIVERSITY EDUCATION TEAM LEADERS}

In psychology, people's personality is divided into four types, namely, active, capable, perfect, and peaceful [1]. Each personality type corresponds to different personality characteristics, and the relationship between the characteristics of the four types of college education team leaders and the team building has an important role in introspecting and improving their own personality weaknesses.

\section{A. Active college education team leader and team building}

One is good at communication. Active leadership is outgoing and likes to interact with people. In team building, it is often able to drive the atmosphere, increase communication between teams, increase communication opportunities between team members, and effectively increase the rationality of decision-making and the efficiency of work between teams[3]. The frequency of communication and the atmosphere of communication and the way in which it communicates have a fundamental impact on the decision-making performance of the organization. The second is passionate. Enthusiastic college education team leaders can use their enthusiasm to drive the enthusiasm of team members to create a good working atmosphere. The third is the lack of rational thinking. Lively leadership personality impulses are more likely to be influenced by emotions, make decisions that are unfavorable for team development, and less consider the feelings of team members, so it is easy to offend others. 


\section{B. Personality Characteristics and Team Building of Leaders in Capability College Education Team}

First, the action is strong. Leaders of competent university education teams are bold and resolute, and often lead the team to complete tasks efficiently.

Second, self-confidence is high. A highly confident college education team leader can not only make members trust the team, but also have strong leadership persuasiveness.

The third is to act recklessly. The emotional and emotional outbursts of the leaders of the capacity-based university education team are very rapid. They are not good at solving problems through thinking and removing obstacles. It is easier to make the wrong decisions because of incomplete thinking.

\section{Personality Characteristics and Team Building of Perfect University Education Team Leaders}

First, strict self-discipline and pursuit of perfection. The leaders of the perfect college education team have a high degree of self-control. They can arrange tasks well in team building, and strictly abide by the established life order and work system, and reduce team mistakes.

Second, emotional control is strong. The leaders of the perfect college education team are good at controlling their emotions, and they will not affect the members' emotions for their own reasons.

The third is of negative sensitivity. Although the communication in the collective is moderate, there is no empty talk. However, the lack of work enthusiasm affects the enthusiasm of subordinates, and avoids difficulties and negative pressures. Their emotions are not exposed, they like to be bored in their hearts, they have a strong sense of self-prevention, they are more likely to be jealous, and they do not trust team members.

\section{Personality Characteristics and Team Building of Leaders in Peaceful College Education Team}

One is easygoing. Peaceful leaders are low-key and kind and are the most introverted type of leadership. They can lower their leadership posture and team members of the team.

The second is to listen to others' opinions. Peaceful leaders are the easiest to reflect on their behavior and behavior, because they like to listen to other people's opinions, and do not impose their opinions on the team, the decision is more representative of democracy.

The third is indecisive and comfortable. Peaceful leadership is calm, but it is slow and lacks determination; it lacks its own ideas and is easy to follow the trend; it is not self-motivated and comfortable with the status. In the team building, there is no prestige, it is relatively impossible to command the team members, and the team lacks an atmosphere of forging ahead.

\section{The Realization of the Personality of the LEADERS OF THE COLLEGE EDUCATION TEAM}

A. Lower the profile in college education teams, and face the weakness of personality

First, be clear about self-positioning. Leaders of college education teams are not superior, but like common members, the leaders of college education teams should clearly define their own position. They should not think that they are better than others. They can send others at will and abuse their power for personal gain. Therefore, the leaders of college education teams can only face their own weaknesses and seek better benefits for the team if they are clearly positioned. Second, correct leadership attitude. Many college education team leaders believe that leadership should be free of mistakes, thus concealing its weaknesses, not facing it and correcting it, so weaknesses may persist and cause an even worse impact in the future. Leaders of college education teams should correct their attitudes toward personality weaknesses, and they will have opportunities to improve and grow, and lead the team to obtain more possibilities. Finally, keep a humble attitude and listen to others. Evaluation is the best opportunity for college education team leaders to correct personality weaknesses because college education team leaders are generally less able to hear subordinates' objective evaluations and point out weaknesses. Maintaining a modest attitude is conducive to getting closer to the subordinates and listening to their subordinates' objective evaluations.

\section{B. Keeping an open mind and change personality weakness}

First, broaden your horizons and reduce leadership limitations. In psychology, people's personalities and temperaments are different. Temperament is an innate trait that cannot be changed, and personality can be changed through acquired training and training. Leaders of college education teams are more difficult to find their own shortcomings and personality deficiencies than the general team members because of the special nature of their jobs. Therefore, the leaders of college education teams should use their networks, books, newspapers and periodicals to broaden their horizons and realize that the world is a diverse combination with many possibilities. Second, keep learning and keep an open mind. There is no boundary in the ocean of knowledge, and most people have limited learning time. If the leaders of college education teams do not constantly learn new ideas and new ideas, they will be self-sufficient, unable to accept the opinions of others, and cannot see their own shortcomings. Finally, take the error as an opportunity to change the character's weakness. Leaders of college education teams, like ordinary people, will have time to make mistakes in decision-making, but in the face of mistakes, many leaders do not reflect on correcting their own mistakes, but to cover up mistakes. Such a leader of college education team will lack the process of reflection and face up to oneself. In fact, the process of finding the cause of mistakes is the process of understanding the character of self. The process of correcting mistakes is the process of correcting the lack of personality. Therefore, the leaders of college education teams need to look directly at their own mistakes, face the shortcomings and shortcomings, and admit their weaknesses in character so that they can urge themselves to make corrections in a timely manner. 


\section{IV.}

THE PERFECT STRATEGY FOR THE LEADERSHIP OF THE COLLEGE EDUCATION TEAM

In addition to the enlightenment of the leaders of college education teams, in addition to the enlightenment of the leaders of college education teams, they must also pass the collective long-term influence and the cooperation of team members.

\section{A. The Perfection of Leadership in College Education Team from the Perspective of Professionalism}

On the one hand, it clarifies the role orientation and functional role of the leaders of college education teams. In general, regarding the positioning of the professional role of the leaders of college education teams, people usually treat them as a profession. The so-called leader role of college education team is the rights and obligations assigned to them by posts[4]. However, just as this society has the same role as the leader of the education team in the university, the occupation has the nuances of non-professional, quasi-professional and professional. Nowadays, the discussion on the role of the leader of the university education team has also been from the perspective of occupation. Positioning, in this regard, various industries have reached a basic consensus. In practice, although each industry has different requirements for the leadership positions of college education teams, the nature of its leadership mechanism is the same, and there are several arguments for its role. Such as "organization leader", "unit authority", "enterprise planner", "project supervision and inspection", "expert", "decision maker", "top executive", etc., are basically based on social economy The practice of the activity is summarized. In the theoretical field, based on the research of different scholars and the challenges and requirements of economic and social development on the leaders of college education teams, this paper summarizes the role orientation of the leaders of college education teams, namely the leadership of "general division". The role positioning path model[5], as shown in the following figure.

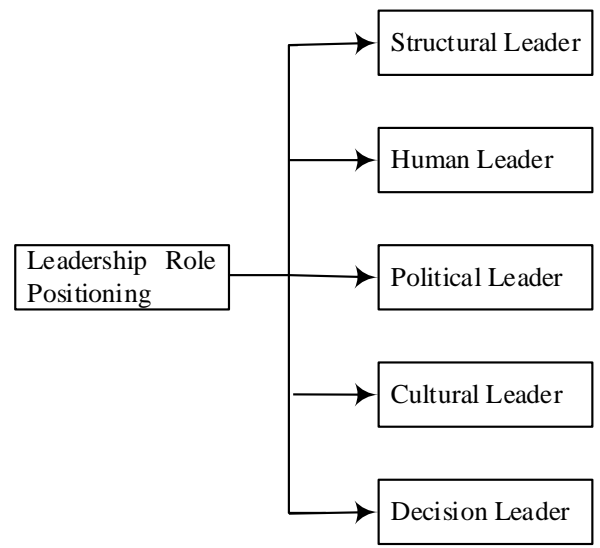

Fig. 1. University education team leader role positioning path model

On the other hand, build a professional standards system for university education team leaders. The above analysis makes us clear the orientation of the role of the leader of the education team in colleges and universities. However, the professional standards of the leaders of the university education team should also be based on the professional role of the leaders of the university education team as the starting point for research, through the internal leadership of professional standards. Requirements, the framework for the evaluation of professional standards for university education team leaders. Among them, the professional evaluation criteria for the leaders of college education teams include two dimensions of content, vertical leadership and horizontal organization - personal aspects. Specifically, the leadership standard at the individual level is the professional quality requirement that the leaders of the university education team should possess from the evaluation system, that is, the content of thought, knowledge, skills, and personality. The development of the leadership standard helps the university education team leaders and team members to interact with each other at work, effectively conduct team meetings, build high-quality leadership teams, and improve the consistency of leadership behavior and team members' execution.

\section{B. The Perfection of Leadership in College Education Team from the Perspective of System}

In order to realize the perfect character of the leaders of college education team in the true sense, and to ensure that the organizational behavior of the organization as the core tends to be specialized, the most obvious and effective guarantee basis is the system construction. To a certain extent, this study finds in the investigation of the leadership character of all walks of life that it is precise because of the lack of the management post system of the leaders of college education teams that the leaders are in the status quo and planning, which greatly hinders the situation. Organizational development [6]. They cannot cope with the changes in the current situation and the development of the environment, and lack the plan to form a complete, supporting and balanced leadership management system. In addition, the establishment of some important leadership management positions is not clear, such as leadership selection and appointment system, leadership performance evaluation system, leadership power supervision system, management compensation, reward and punishment system. The establishment of these systems lacks scientific arrangements. Over time, it will have a great negative impact, affecting not only the leadership appointments, assessments, remuneration, rewards and punishments involved, but also the soundness of the existing leadership management system.

\section{The Perfection of Leadership in College Education Team from the Perspective of Subject}

Taking the leader of the university education team as the main body, regardless of the incumbent leadership or the incumbent university education team leader, the organization's requirements for the leaders of the university education team need to strengthen their sense of responsibility in all stages of development, and profoundly grasp the university The direction of the cultural team leader's character connotation, and strive to improve their leadership. As mentioned above, leadership is the embodiment of the specific duties of the post, and the responsible subject of overall management for a specific purpose. The character of the leader of the university education team is the internal driving factor that influences the work behavior and work ability of the leaders of the education team in the university. In essence, both of them point to the realization of organizational goals [7]. 
With team members as the main body, team members as the direct subordinates of the leaders in the organizational unit should respond to the leadership and decision-making of the leadership to the greatest extent. The firm follow-up has become a key factor in the team's operation process. The implementation of organizational tasks and the completion of organizational performance have a non-negligible impact [8]. Different character leaders will build different types of team styles, with different types of followers. However, in view of the different abilities and traits of team members, the leaders of college education teams should always consider selecting matching leaders to maximize the understanding of team members and let team members release the greatest potential and maximize team building. Value can achieve good team effectiveness [9].

\section{CONCLUSION}

This paper analyzes the relationship between the leadership character of college education team and team building through personality classification theory and leader related theory. According to the analysis, the leaders of the university education team want to build a high cohesiveness and high-efficiency team should lower their posture, face the weakness of the character, maintain an open mind, and change the character weakness. In addition, it puts forward the perfection strategy of the leaders of college education from three perspectives: professional perspective, institutional perspective and subjective perspective, and looking forward to providing enlightenment and reference for the development of their own personality in today's college education team leaders.

\section{REFERENCES}

[1] L. Jon, M.C Naughtan, D.P. Brooke and D. Elisabeth. "The road already traveled: communication advice for higher education leaders," International Journal of Educational Management, vol. A6, 2019.

[2] E. Festus and O. Biakor. "Interactions with Asians in Higher Education: Beyond Multicultural Myths,” Multicultural Learning and Teaching, vol. A2, 2019.

[3] H. Loomes, F. Owens and M. Carthy. "Patterns of recruitment of academic leaders to Australian universities and implications for the future of higher education,” Journal of Higher Education Policy and Management, vol. A2, 2019

[4] S. Divya. "Modeling systems thinking in action among higher education leaders with fuzzy multi-criteria decision making," Management \& Marketing, vol. A13, 2018.

[5] Li Jingjing and Cha Shijun. "The construction of academic leadership in colleges and its application in higher education evaluation," Education for Higher Education in China, vol. A29, pp. 26-28, 2018. (In Chinese)

[6] A. Sarah, R. Thompson and L. Karen. "Disruptive trends in higher education: Leadership skills for successful leaders," Journal of Professional Nursing, vol. A34, pp. 2-5, 2018.

[7] K. Yenney. "A Guide for Leaders in Higher Education: Core Concepts, Competencies, and Tools," Journal of Student Affairs Research and Practice, vol. A55, 2018.

[8] Zhu Yu, Wang Lingjuan and Li Qianqian. "Leader's Psychological Capital, Leadership-Member Exchange and Team Member Innovation Behavior: Theoretical Model and Empirical Research,” Foreign Economy and Management, vol. A37, pp. 36-51, 2015. (In Chinese)

[9] S. Johar, S. Abdullah, M.A. Yusoff, R.M. Suhaimy, K.A. Isa and K.Ismail. "Emotional intelligence dimension on self-esteem of employees through the personality of leader," International Journal of Engineering and Technology, vol. A24, pp. 1161-1166, 2018. 